Meta

Journal des traducteurs

Translators' Journal

\title{
Quelques termes d'assurance sur la vie
}

\section{Jean-Paul de Grandpré}

Volume 17, numéro 3, septembre 1972

URI : https://id.erudit.org/iderudit/002961ar

DOI : https://doi.org/10.7202/002961ar

Aller au sommaire du numéro

Éditeur(s)

Les Presses de l'Université de Montréal

ISSN

0026-0452 (imprimé)

1492-1421 (numérique)

Découvrir la revue

Citer cet article

de Grandpré, J.-P. (1972). Quelques termes d'assurance sur la vie. Meta, 17(3),

167-169. https://doi.org/10.7202/002961ar d'utilisation que vous pouvez consulter en ligne.

https://apropos.erudit.org/fr/usagers/politique-dutilisation/ 


\section{QUELQUES TERMES D'ASSURANCE SUR LA VIE}

Administrateur - director - Membre du conseil d'administration d'une compagnie ou société. Le calque «directeur », omniprésent dans les vieux textes de loi, est fautif. Le directeur, en effet, n'a pas pour fonction de gérer les affaires d'une société, mais de diriger le secteur qui lui est confié. Voir aussi : directeur.

Affaire réalisée - written business - Proposition recueillie par le producteur, mais dont le risque n'a pas encore été tarifé. "Écrire» au sens de réaliser est un barbarisme. Les expressions « affaires écrites », «écrire des affaires 》n'appartiennent pas à la bonne langue. Voir aussi : réalisation.

Cadres - officers - Ensemble des chefs d'une entreprise (Robert). Les cadres se répartissent en trois catégories : 1) les cadres supérieurs (top management) ; 2) les cadres moyens (middle management) ; 3) les cadres subalternes. Voir aussi : cadres de direction.

Cadres de direction - executive officers - Ensemble des chefs d'une entreprise constituant la haute direction. Voir aussi : cadres. 
Directeur - manager - Celui qui dirige. Il y a dans les compagnies d'assurance le directeur général (general manager) et les directeurs des différents services (department managers) : directeur commercial, directeur administratif, directeur technique, directeur du personnel et d'autres encore. Souvent ces expressions peuvent utilement servir à traduire des titres anglais où cette langue utilise les termes superintendent, officer, executive et même secretary (voir ce mot). Forme fautive : " gérant». Voir aussi : directeur commercial.

Directeur commercial - superintendent of agencies - Personne chargée de la direction des services commerciaux. L'implantation, récente dans le domaine des assurances, de l'expression director of marketing semble répondre à une conception où l'aspect technique de la production prime l'aspect purement commercial. Voir aussi : directeur.

Établissement - issuing - Action de préparer, de rédiger une police, un avenant. Voir aussi : Cahier $n^{\circ} 3$ de l'Office de la langue française, établir.

Police régularisée - placed business — Contrat à l'égard duquel l'assureur se considère définitivement lié (placed under the risk). Pour produire ses effets, une police doit être régularisée. Le calque "placer», utilisé dans ce sens, peut induire en erreur. Placer a en effet un sens beaucoup plus large : celui de vendre des valeurs, des marchandises, etc. Placer un contrat, c'est réaliser une affaire au sens général du terme sans l'acception administrative. Ainsi pourrait-on dire : en juin cet agent n'a placé aucun contrat, mais six des contrats qu'il avait réalisés en mai ont été régularisés. Voir aussi : régularisation.

Prime de production - annual premium value - Prime servant de base au calcul des commissions et des gratifications servies à l'agent. La prime de production s'obtient par un mode de comptabilisation particulier. Elle est souvent différente de la prime payée par l'assuré. Le mot production prend ici une acception d'ordre administratif. Le calque «valeur de prime annuelle » parait obscur et inutilement long.

Réalisation - Action de recueillir des propositions qui seront ensuite soumises à l'assureur pour que le risque soit apprécié. Dérivé : réalisateur (agent of record).

Régularisation - placing - Action de mettre en règle. Voir aussi : polices régularisées.

Secrétaire - secretary - Celui qui, notamment, s'occupe de l'organisation et du fonctionnement des assemblées du conseil d'administration. Il convient de noter ici l'acception prestigieuse que l'anglo-américain tend à donner à secretary. Ainsi il existe à Montréal une société où une seule et même personne dirige les services de la tarification, des sinistres et des archives; son titre : underwriting secretary. L'expression directeur technique, utilisée par le traducteur ${ }^{1}$, semble correspondre parfaitement à cette réalité.

Secrétaire administratif commercial - agency secretary - Employé qui assume les tâches administratives du service commercial. "Secrétaire d'agence »

1. Il s'agit de M. Denis Nehmé. 
est fautif dans ce sens puisque cette expression sert à désigner une autre fonction, de niveau subalterne. Voir aussi : secrétaire d'agence.

Secrétaire d'agence - branch secretary - Employé qui assume les tâches administratives d'un bureau régional ou agence.

Sélection - selection - Opération par laquelle l'assureur exerce un choix parmi les risques qui lui sont proposés. Synonyme : appréciation. Le mot tarification qui éclaire une facette légèrement différente de l'opération en question est aussi à retenir, d'autant plus que son dérivé tarificateur (head office underwriter) comble une lacune de la terminologie canadienne des assurances. Voir aussi : Cahier $n^{\circ} 3$ de l'Office de la langue française, tarificateur, tarification.

Services extérieurs - field organization - Réseau de bureaux ou d'agences mis en place pour assurer le recrutement de la clientèle et le service. L'expression field man par laquelle on désigne les vendeurs dans l'intention de les opposer aux «théoriciens » du siège social serait avantageusement rendue, nous semble-t-il, par praticien. "Homme du champ» est en tout cas à condamner. Voir aussi : terrain (sur le), META, XVI, 3.

JEAN-PAUL DE GrandPré 